\title{
Being a Video-Choreographer: Describing the Multifaceted Role of a Choreographer Creating Screendance
}

Heike Salzer, Artistic Director of Salts

Ana Baer, Artistic Co-Director of the Sans Souci Festival of Dance Cinema

This is a conversation between Heike Salzer, Artistic Director of Salts and Ana Baer, Artistic Co-Director of the Sans Souci Festival of Dance Cinema. They talk about the creative process of a videographer, the Sans Souci Festival, and the importance of screens, audiences and legacy.

Heike Salzer-On your website you call yourself a video-choreographer. Can you tell me what you mean by that and why you define yourself by this term?

Ana Baer-I am choreographing on the stage as well as in my video work. When I create video work, for the most part, I am creating videodance, (also known as screendance), I am not documenting. I am making dance for the camera. That's why I thought it would be appropriate to call myself a video-choreographer.
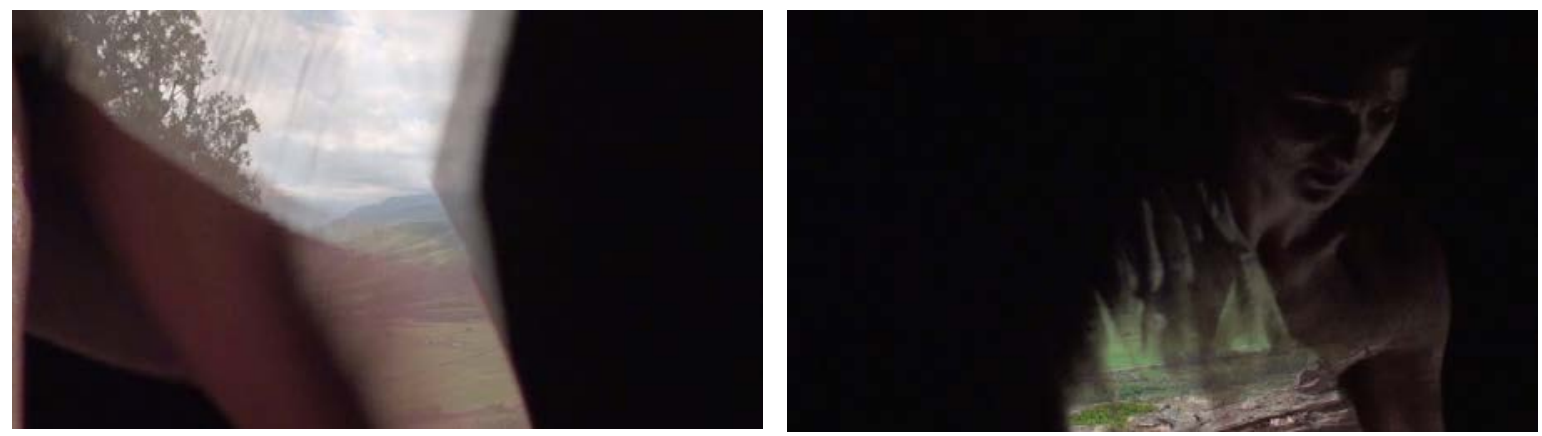

Images from Disappear here, courtesy of the artist

HS-Does it feel like choreography on the screen?

$\mathrm{AB}$-Yes, very much so. Sometimes I choreograph for the stage and that is where the work lives. Other times I choreograph a piece knowing that I will re-organize and manipulate the material during the editing process. When editing one manipulates the same elements used during the choreographic process of a live piece, elements such as 
time, space, dynamics, speed and spatial composition, in addition, one incorporates the movement of the camera, as well as the composition of the frames. Even though the body in movement is the seed and inspiration of screendance, often the movement phrases get tossed around, the end becomes the beginning, the body gets fragmented and layers of dancers end up superimposed into different backgrounds, creating a new work which in some cases is far apart from the movement material that it was based on. My decisions are based on the rhythm and composition of the new hybrid piece, as well as on the design, contrast and the proximity to the camera. That is what I experienced when creating the screen dance disappear here (2010). Initially I filmed two dancers in the black box, with the assistance of my colleague Caren McCaleb subsequently, we filmed a group of dancers at the mountains of Colorado. In the finished product, one can see segments of movement phrases superimposed into a slow procession of dancers on the top of the mountains, creating a visual metaphor.

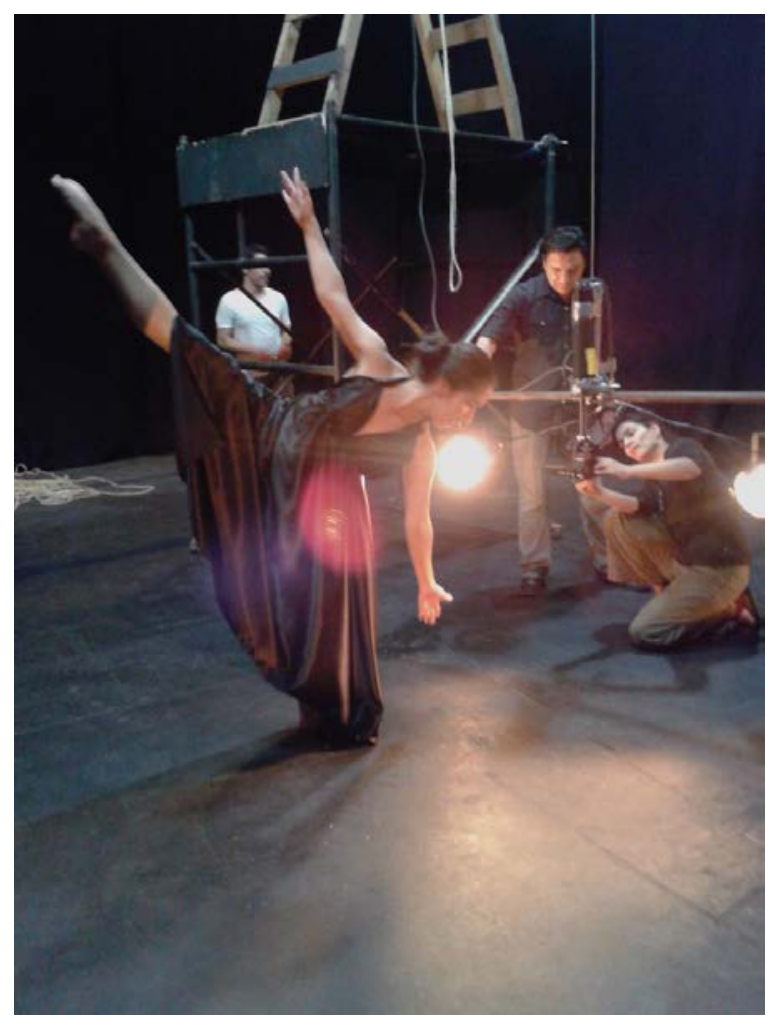

Ana Baer filming Rocio Luna and dancers from La Universidad Michoacana at the CEDRAM in Michoacan, Mexico, 2013. Image courtesy of CEDRAM

HS-Can you tell me more about your creative process?

$\mathrm{AB}$ - In the beginning when I moved to the States, it was very important for me to talk about my nationality, my upbringing and my culture. I created political work in which the theme and the movement invention based on such theme were pivotal elements of the creative process. Common themes of my earlier work include poverty, injustice, 
impunity and similar socio-economical issues. I created pieces about murders in border towns, tortured women and kids that lived in the streets among other topics. I was intrigued by the similarities and differences between Mexico and USA, but at some point the line started to blur, and political issues were not as essential to my creative work.

I started my Masters Degree at the University of Colorado in Boulder, and was invited to take experimental film classes with Phil Salomon, to date, one of the strongest influences in my work. I started exploring the intersection between choreography and video. I don't have a specific technique for creating. Every piece presents a different challenge, different vocabulary, and different approach. The common denominator is my investment in the exploration of dance and projecting images. In order to better explore the intersection between these two elements I study my dancers strengths and affinities, since this will be the main element of my work and will inform the creative methods in the development of the material. As important to the process is the familiarity with my film equipment and editing software, and when presenting live dance with projected images, the space design of the venue becomes vital to the work as well.

HS-Would you call it a collaborative process with the dancers?

$A B-Y e s$, very much so. There needs to be exchange; their bodies have so much history, the way they move reflects their training, their preferences, their affinities, their similarities with other dancers as well as what makes them unique; my job as the choreographer is to provide them with a space for exploration and to guide them so we can generate material for each unique work.

HS-Can you give an example of how you allow space for exploration, while at the same time you ensure that the dancers keep on track with your idea?

AB-During my latest choreographic work in 2014 with college students at Texas State University called do not flinch, I created a few movement phrases which I taught to them. Once they have learned the phrases, I asked them to manipulate them based on their own preferences, allowing them to choose the way in which they transform them. Lastly, I asked them to transform the material into duets, and trios. By the time they showed me the trios, there was only a trace of my movement and many variations ready to be tweaked again by explorations of dynamics, intention or form and then set in space. 


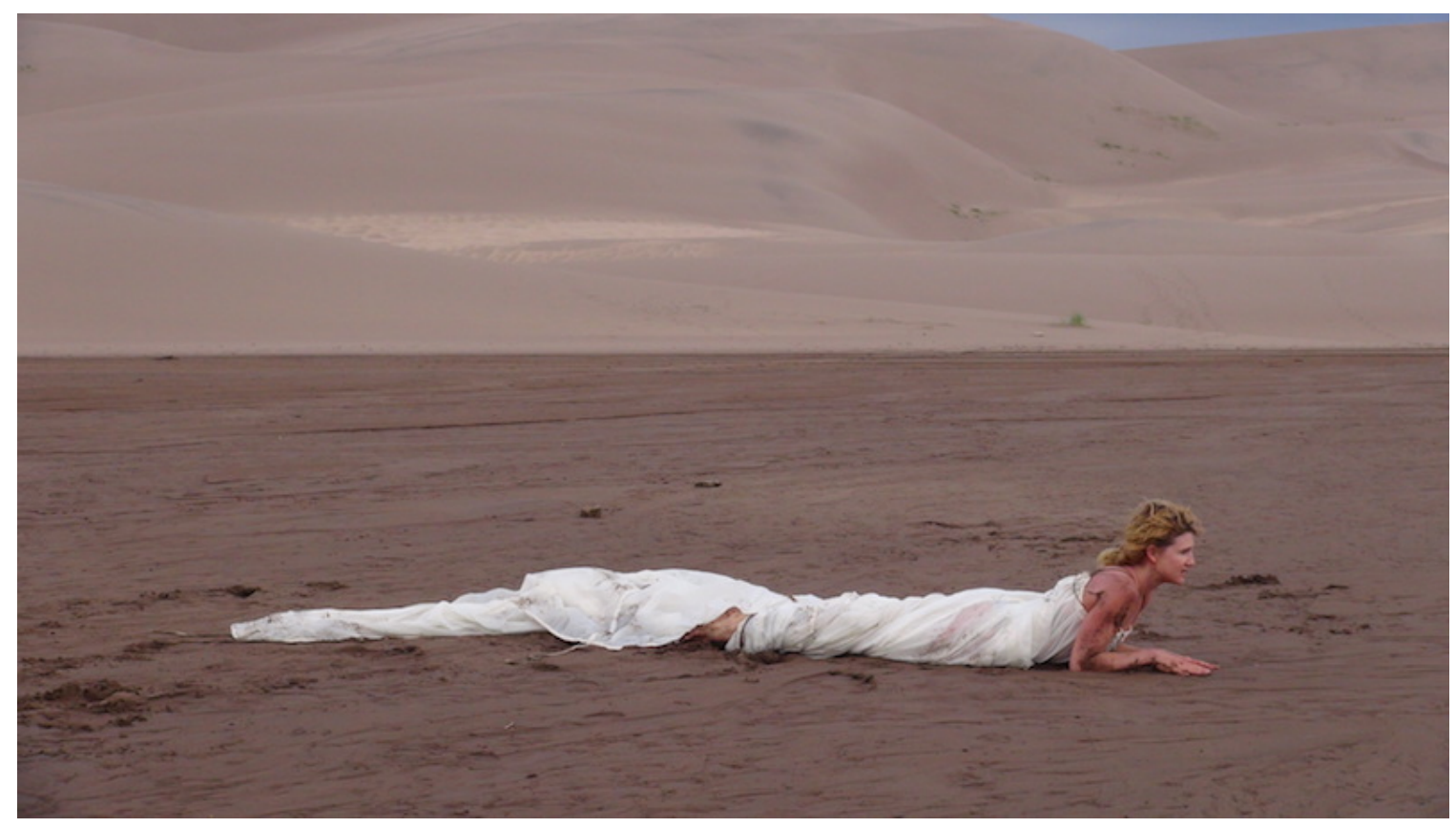

Ana Baer filming Kim Olson at the Great Dunes, Colorado, USA. A collaborative project with Syzygy Butoh and Sweet/Edge, 2014. Image courtesy of Ana Baer.

HS-Do you work out of a location or narratives?

$A B-I$ would say both, out of a location, and also out of a combination of both, narrative and location. Some of my work is mainly an exploration of the location, a site specific work that could have not been created elsewhere. Such is the case of my piece Dunes (2014), an exploration of the female moving body in an extreme environment. This category of screendance is common practice among the field. Such is the case of the breathtaking piece The Time it Takes (2013) by Katrina McPherson and Simon Fildes, in which they explore an archaeological find in the Outer Hebrides, Scotland. In this same category of site specific screendance we find the work North Horizon (2010) by Thomas Freundlich and Valtteri Raekallio, exploring the Arctic landscape of Kotka, Finland, as well as the piece $1 / 6$ (2009) by Orsola Valenti, an exploration of snow and fir trees in Switzerland, or your work Strönd/Beach (2010) where the dancers were filmed on two beaches in Iceland and Denmark and then edited together on one screen.

HS-Yes, in Strönd one could say that the different cuts from one location to the other, the shots themselves become sites which interact with each other. The locations were not only the impulse of our movement, but also the way we filmed and edited the piece. 

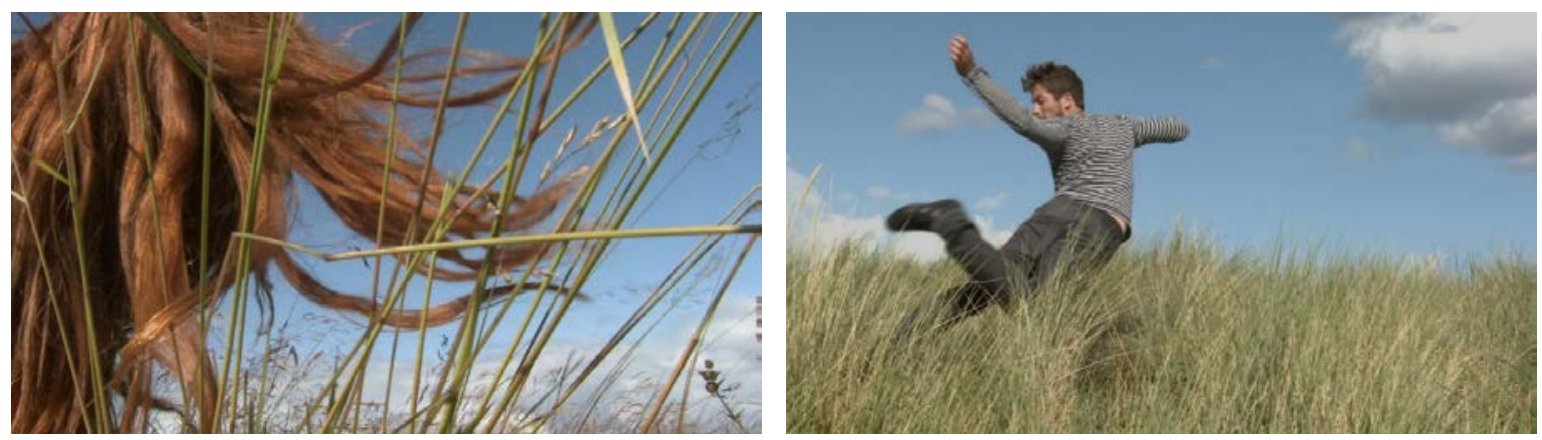

Images of Strönd/Beach, Dir. Heike Salzer and Ingi Jensson. Perf. Saga Sigurðardóttir and Søren Linding Urup. 2010. courtesy of Heike Salzer.

$A B$ - Another category of screendance involves a narrative or situational piece; such is the case of Home (2014) our first collaboration. In this piece, first we scouted the train tracks and subsequently, we explored the location. We had been shooting for some hours when a train passed really close. In this case, the narrative developed out of the situation. If the train would have not passed, the piece would be completely different. Other examples of powerful narrative or situational screendances are: Emile Shemilt's A Touch of Red (2013), where a relationship is revealed through performative and cinematic patterns, rhythms and expressions; and Tove Skeidsvoll \& Petrus Sjövik's Outside in (2011), where the dancer Cecilia dances inside a forest inside a studio introspectively filmed by an intrusive crew.

HS-Filming on sites offers the opportunity to improvise as a team. Different to the stage, where the environment is controlled, shooting dance on sites has an exciting side effect, it is uncontrollable; the weather changes, animals or objects such as the train in Home appear. These unexpected moments offer the chance for dialogue between the environment, the dancers, and the filmmaker. Creating material informed by an occurring situation allows reacting in the moment and making creative decisions based on an immediate embodied experience. The train track shoot for Home would have been very different if the train would have not appeared. For me, as the performer this visceral experience of the location, allowed me to react 'site' and 'situation specific.' Improvising in the moment and following my instant associations stimulated by the energy and force of this fast, heavy steel object. I could feel the wind and the vibrations of the ground, affecting my body when it rushed by. There was no time to communicate with each other about how you would capture this with the camera, but I was sure that you would react and would follow; we were both improvising in reaction to the third 'moving element,' the train! 

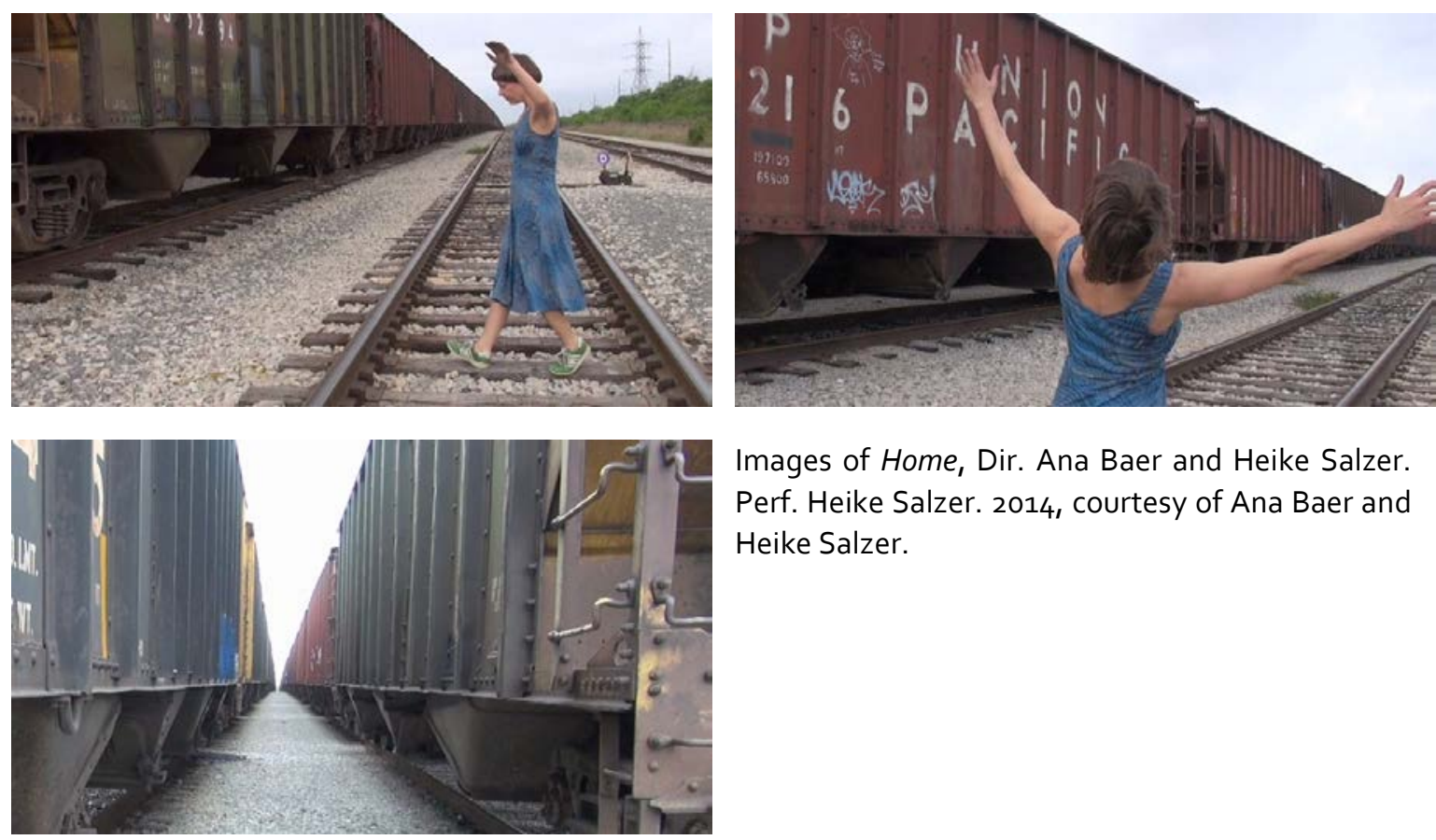

Images of Home, Dir. Ana Baer and Heike Salzer. Perf. Heike Salzer. 2014, courtesy of Ana Baer and Heike Salzer.

HS-How do you approach post-production? Are there any specific aspects, which are important to you in the editing process? You already mentioned that you are becoming a choreographer again.

AB-Firstly I need to know what my footage is. I study it, select it analyze it and name it. Sometimes the footage that I thought was great is not so good, and in the same way, some footage surprises me for its definition and design. Often I film with an idea of what I would like to explore in the editing process, but regardless of how much insight I have regarding the editing process, I try to over shoot, I shoot much more than what I think I will need. Once on the editing process, I start exploring by moving sequences out of order, or repeating some elements of the phrase, then I manipulate the speed, the size, or the colors, as needed. I see what flows and what doesn't. After I have a first draft, I get some music that I enjoy and that provides me rhythm and some sort of structure. However I almost never use this music, due to music right issues and because I don't want the music to correlate as directly to my edit, so I usually commission a composer to create and original score that can enhance the movement without mimicking.

HS-This process that you describe is, as if we choreograph movement images similar to bodies in space. Firstly when choreographing the movement with the dancers, then when we capture and frame the movement in the filming and finally when we are editing. Each process allows the videographer to think with a choreographic mind, looking at anything that is moving as a 'body' that is choreographed. This includes not only the bodies of the dancers, but also the space that is captured around the dance in 
the two dimensional frame, for example the environment, architecture, or objects, and during the editing the ways in which superimposing, layering or split screen can create a composition of the different elements on the screen. In each process we are thinking of space, time and effort, composing different layers of moving images.

$A B-I$ agree, and should add that chance and/or intuition play a great part on the whole process.

HS-Do you spend more time editing than filming?

$A B-Y e s$, infinitely more. I usually try few editing ideas before selecting the appropriate one for each piece. Some ideas are very simple like fragmenting a phrase and moving it out of order, or manipulating the speed; however, some other ideas are more complex and time consuming like chroma-keying part of the background or applying an effect with different intensities throughout a clip. There is also the possibility of re-visiting a finished piece, and re-editing, so there is no limit to how much time you can spend on certain pieces.

HS-You also create work where you combine live performance and screen-based work. What kind of relationship do you think those two elements have?

$A B-I$ am very invested in it and have been exploring ways to integrate both elements. I've experimented with proximity in space, bringing two elements very close. For example when I project the image on the dancers.

HS-Can you elaborate what kind of integration this has created?

$A B-I n$ this particular example I am trying to integrate both elements in space. When there is a projection on one side of the stage and a live dance on the other side, most of the audience will prefer the projection. When superimposing the image into the dancers, you capture the audiences' full attention. Another possibility is sharing the elements on the video projection and on stage (making the work self referential). For example, we could project the same dancers as a linking element and experience them both, live and on the screen, this could happen simultaneously or at different times in the piece.

HS-A great example of such a strong visual link between live and virtual dancers and the choreographic composition is the piece Proximity (2013) by Choreographer Garry Stewart and Video Artist and Engineer Thomas Pachoud developed for the Australian Dance Theatre. Here the live and virtual dancers are in a dialogue with their counterparts via real-time video manipulation. It is not only the play with perspectives which creates the strong connection between the projections and the dancers on stage but also the awareness that real-time manipulation is taking place, such as delayed and manipulated projections of the live dancers. 
While this is an example that uses an obvious link between the live and projected image, sometimes, it is a degree of how much of that is needed in order to integrate the experience of the live dance and the projecting image for your audience. There must be a connection, however the link could also be thematic or even a contrasting connection, a juxtaposition of movement and image.

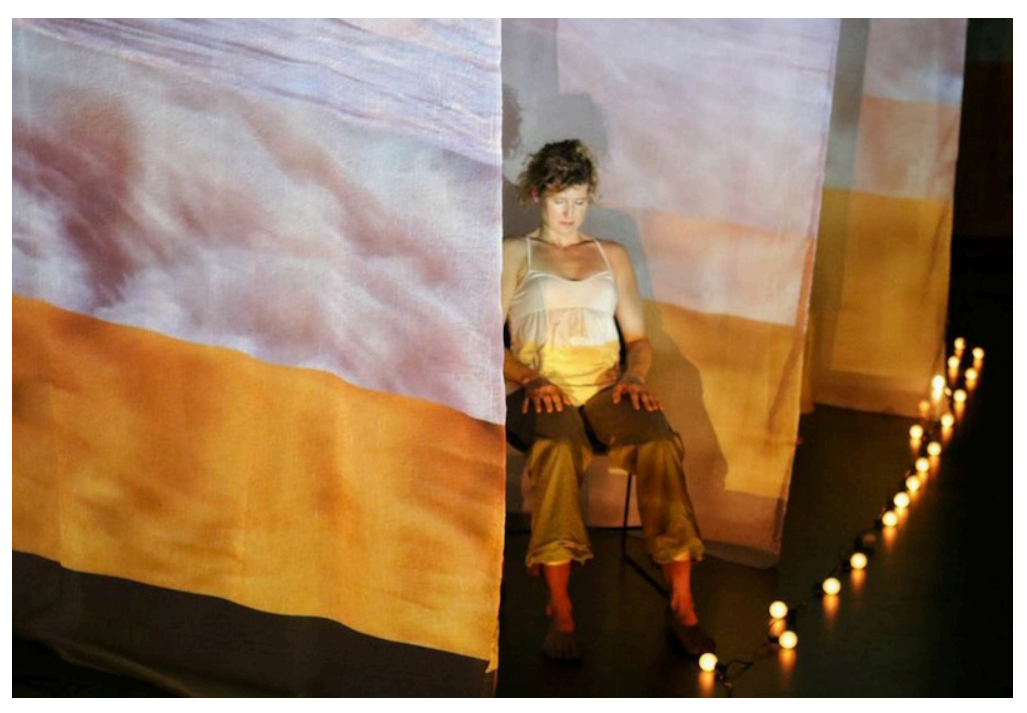

Image of OJO, Chor. and Perf. Kim Olson. Vid. Dir. and Ed. Ana Baer. 2014 courtesy of Ana Baer.

AB-For example my latest multi-disciplinary collaboration OJO (2014) where the dancers were moving on a vast stage without a sitting area or a "front," the projected images of different stripes of water were projected on the dancers and on flying pieces of fabric, bringing all the attention to this particular part of the stage. The projected water contrasting the rest of the elements created a visual counterpart to the movement.

If one doesn't incorporate and create a relationship between the projecting image and the live performance, the audience attention drifts towards the video, and this has been one of my creative enquiries of study.

HS-What is it that fascinates you with screen-based work?

AB-Mainly, two aspects, the massive difference of accessibility between live performance and screen dance, and the aspect of ephemerality. When working for a stage performance, the work vanishes after you perform it, not so when you create a dance for the camera.

HS-Is impact and reaching the audience something that you are interested in? Is that kind of legacy important for your work? 
AB-Yes! When I learned that this was a genre that I could access, I was excited about the potential reach and accessibility of this medium. I am interested in experiencing other cultures and I travel as much as I can, that said, I can't always bring dancers with me to perform my work. Screen-based work travels light. I find it intriguing that people in remote places are accessing my work and the work of the Sans Souci Artists, and in a similar way, I am fascinated by work of artists from other parts of the globe.

HS-Do you think the medium itself is more accessible because it is on the screen, something we are maybe more familiar to? Does perhaps the length of shorter videodance pieces play a role?

$A B-W e$ are a YouTube/Vimeo generation and the youth is familiar with the genre. Currently, screendance is a fertile field, it is interesting for them, because it is technology, and they know and use technology, they know videos and they can access them all the time. Most commercial dancevideos are created to illustrate pop songs; they are short (3-4 min). At the Sans Souci Festival we favor videos that are shorter than $15 \mathrm{~min}$, mainly because we want to screen a representational sample of each year's production, but we've shown many that are longer.

HS-Considering that there is constant access to media and videos via digital devices, if any, what effect does this have on your work? Does it influence the outcome of your work?

$A B-Y e s$ and no. I feel that each piece dictates its own length. But in general my pieces are short, and maybe this is endemic of our times.

HS-This reminds me of Bob Lockyer's observation when comparing stage performance with dance on screen. He suggested that "... stage time and screen time are different". ${ }^{1}$ Time on the screen appears to pass much faster than in a live performance. It also seems that the size of the screen influences the perception of time, as smaller the screen as quicker time seems to pass.

You have been co-directing the Sans Souci Festival of Dance Cinema based in Boulder, Colorado for 11 years. What are the criteria that you select the video for screening?

AB-As our mission states it, we support new work that integrates dance with cinematic elements, both experimental and traditional. We also encourage an expansive definition of dance and encourage an appreciation for highly experimental and interdisciplinary forms, including mixed-media works that incorporate live performance.

HS-Do you consider the audience during the curation process?

AB-Yes, I curate with my audience and venue in mind. Some of the aspects that I consider are our audience's age, their exposure to the medium, as well as the duration 
of the event and the size of the projecting surface. For example when I screen the festival to college students, I don't select many long and slow developing videos, instead I tend to show fast-paced, fun and/or uplifting videos. I include videos in which they can identify themselves with the dancers on screen either because of their similar age, or because they share the same dance practice. However, I usually include videos to challenge their pre-conceptions and inform how expansive the genre can be. In Mexico for example, due to the political environment that they are living in at the moment, I try to bring videos that have an emotional, cultural or social content.

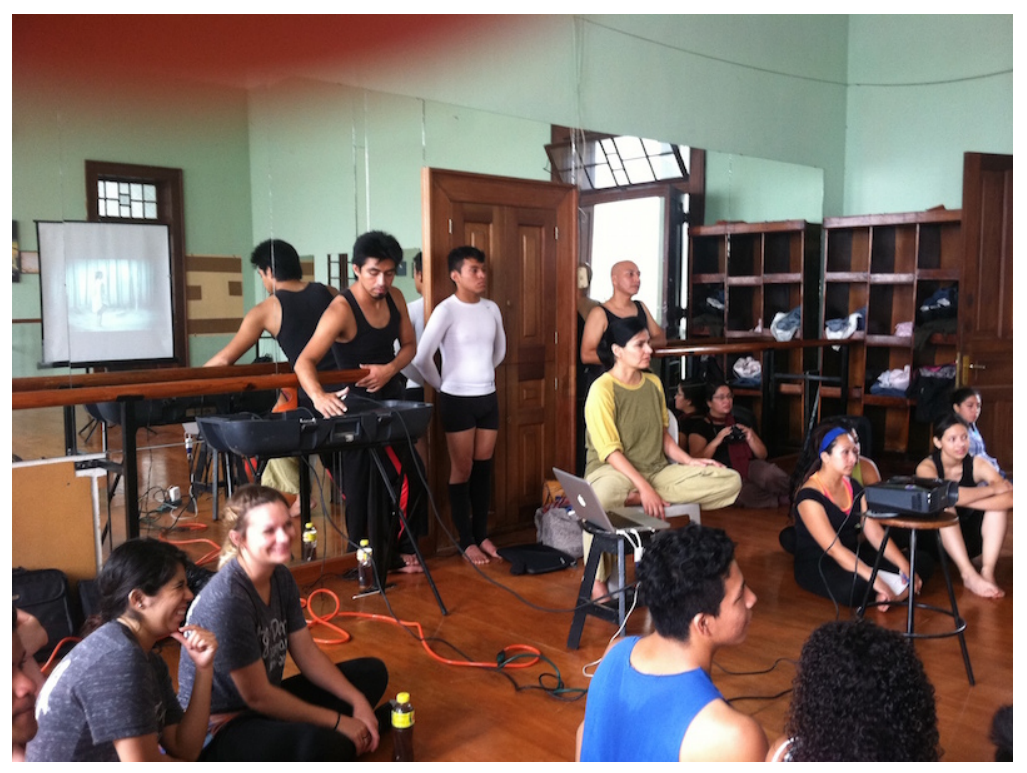

Screening of Sans Souci Festival of Dance video selection at the Universidad de San Carlos, Guatemala City, Guatemala, 2014. Image courtesy of Universidad de San Carlos

HS-It is interesting that you consider the political environment of a particular community. Can you elaborate how the expectations of the audience in for example Mexico influences the way you curate the program?

$\mathrm{AB}-\mathrm{I}$ have produced the Festival in the State University of Morelia, Mexico on three occasions. The audience is comprised of their wonderful dance department, students that are dealing directly or second handedly with violence, poverty and constant impunity by their local authorities. It has been my experience that they are expecting work that is not only aesthetically pleasing, but work that has an emotional or cultural investment. Last year I screened Off Ground (2013), directed by Boudewijn Koole, among other pieces, they were deeply touched by this masterful screendance, they could relate to the pain, the loss, the emotional development of the piece. When I screen this same piece to my college students at Texas State University, they are moved by it as well, but they rather watch work that includes hip-hop dancers and lighter themes. As a curator, my role is to screen the kind of work that the audience 
expects, as well as pieces that I think might challenge them, in order to expand their appreciation of the form.

HS-To what extent do you feel you can develop and support and foster a screendance community?

$\mathrm{AB}-\mathrm{I}$ feel like this is my role and my biggest contribution to Sans Souci Festival. Introducing this hybrid and relatively new medium to students as a new practice, continuing to produce the festival in venues that have a consistent interest for the form as well as in new and remote venues are in the forefront of my work.

HS-The Sans Souci Festival receives entries from all over the world. Do you notice any trends over the years?

$A B$ - In general, I would say that the production value is increasing, more artists are involved in the production of a screendance. The inclusion of dance forms, (asides from the prevalent modern/contemporary form), like hip-hop and neoclassical dance in the last past years could be read as a trend. Maybe the incorporation of animation could be a trend as well.

HS-In terms of recognition, how do you experience where videodance is placed?

$\mathrm{AB}-\mathrm{I}$ think that the field has been consistently gaining recognition. The proliferation of screen dance festivals as well as scholarly journals dedicated to this hybrid form, such as the International Journal of Screendance, have seeded a period of growth. The youth is fluent in technology and hungry for some substance. At the same time, the production value has been increasing and with it, our audience base. For example, The Sans Souci Festival has been screening at the interdisciplinary venue ATLAS Institute in Boulder, even though most of our audience is from a dance background, year by year, we are making new connections with Film, New Media, English and Music majors, (to name a few), as well as with the general audience. During the last few years our audience has increased significantly, so we decided to add a few more venues to screen the work in the City of Boulder. In 2014, we screened in 3 additional venues plus 2 more out of state venues. The interest in the Festival has been increasing since our inception in 2004. The international screenings have also been increasing. We are constantly looking for co-producers and partners in order to expand our reach and show the work of our Artists. Currently we are working on co-producing the Festival in the UK and Iceland.

HS-You also have exhibited programmes in more informal public settings such as the library. Our project Bekkur/Baenk 1,2,3... (2010) was screened in cafes in Reykjavik and Copenhagen. To me these alternative public spaces, offer the opportunity to screen work over a longer period of time and visitors enter these spaces for other reasons, therefore stumbling upon screendance out of coincidence. I think this unexpected 
encounter might raise the awareness of the genre, creating interest, and an audience who then might consider coming to a festival or viewing work online.

HS-The artists who are submitting to your festival, do you know, what their background is?

AB-They are truly varied; from the choreographer creating their first choreography for the camera, to the experienced dance maker collaborating with cinematographers and composers; from the inexperienced student that recently took a final cut pro course online to the production company working with established dance companies, that is the beauty!

HS-Does the screen size influence the programme you curate?

AB-The ATLAS Institute where we annually produce the Sans Souci Festival has fantastic projection quality and we usually screen two one and a half hour programs, (one on Friday, and the next on Saturday night). We have experimented with longer programs resulting in an overwhelmed audience, and we can't screen a shorter event due to the amount of fabulous work that we want to show. I think the smaller the screen size, the shorter the event. If you are watching on a small screen you are expecting a YouTube video, one short video after another. If you have a big cinematic screen the viewing expectation is longer, similar to a movie in a cinema.

HS-What is the next thing that you think you would love to do? In terms of your own work or the festival.

AB-For the festival, I'm glad that it is growing and that I can contribute with International screenings. Traveling with it is important for me. This year I'm going to Guatemala and that's a new venue for the Festival, the first time that most of our artists' work has been screened there. I've never been in Guatemala so I'm excited to experience the culture. I want to see what experience and reactions the audience will have with the different programs. I enjoy bringing the Festival to remote places where this might be their first exposure to the medium, creating community and encouraging cultural exchanges. I also enjoy intimate venues where there's room for $\mathrm{Q} \& \mathrm{~A}$, adding an educational element to the screenings. Sans Souci Festival of Dance Cinema has been able to create space in Boulder, to foster community among the college students and the general audience, breaking a barrier that sometimes is hard to penetrate. My goal is to foster other long-term relationships and to enhance other communities by offering annual screening, workshops and/or lecture demonstrations elsewhere. In doing so, we are advancing the field, screening the work of a multitude of international artists in different parts of the globe, as well as creating community, fostering international collaboration, and educating.

In terms of my own work, at the moment I am experimenting with a few things in choreography, such as the integration of partnering work with multiple facings, and the 
juxtaposition of slow stationary movement against a fast traveling phrase, as well as the introduction of pedestrian movement gestures combined with technically challenging phrases. I also keep investigating the relationship between projected image and live performance. Recently, I have been projecting images in unusual surfaces, such as the dancers themselves, or hanging elements through out the stage in an attempt to break with the bi-dimensionality of a flat screen. Going to a different country to screen Sans Souci and create work with other artists is a treat for me!

\section{Biographies}

Ana Baer is a Mexican video-choreographer living in the USA. Her work encompasses a variety of dance for camera work, as well as interdisciplinary performances and choreography. She has been Artistic co-Director of Sans Souci Festival of Dance Cinema since 2004 and is a founding member of Avant Media, Bitcho Maria Productions and Merge Dance Company. In 2013 she co-founded the transdisciplinary collective Xinergistas. In 2014 Heike Salzer and Ana Baer formed the Transatlantic Multidisciplinary Collective WE Create Productions, in order to explore creative collaboration within the confines of arts and technology. Ana is currently teaching as Associate Professor at Texas State University, San Marcos, Texas. www.anabaer.com; Sans Souci Festival of Dance Cinema.

Heike Salzer is a German dance artist currently based in the UK, where she is Program Leader of the dance degrees at Teesside University, Middlesbrough. Under the name of Salts she collaborates with numerous international artists; many projects have been with the Icelandic visual artist Ingi Jensson. Her work has taken various forms, from live performance and dance videos to installation work, and has been invited for performance, screenings and exhibitions at international venues such as the Sans Souci Festival of Dance Cinema (USA) where she and Ana met. Heike is co-artistic director of Tees Dance Film Fest (UK). www.salts.nl

\section{Notes}

${ }^{1}$ Lockyer, Bob, "A new place for dancing," In Envisioning Dance on Film and Video, edited by Judy Mitoma, Chapter 28, 156-162. New York: Routledge, 2003. 


\section{References}

1/6. Dir. Valenti, O. Chor. Van Acker, C. 2009.

A Touch of Red. Dir. Shemilt, E. Chor. Guarino, N. 2013.

Disappear here. Dir., chor., and ed. Ana Baer. 2010. http://anabaer.com/disappear-here/

Do not flinch. Chor. Ana Baer. 2014.

Home. Edit 1. Dir. Ana Baer. and Heike Salzer. Ed. Ana Baer. Chor. and Perf. Heike Salzer. Comp. Jeff Mohler. Prod. We Create. 2014. Vimeo.

Home. Edit 2. Dir. Ana Baer and Heike Salzer. Ed. Chor.and Perf. Heike Salzer. Comp. Jeff Mohler. Prod. We Create. 2014. Vimeo

Lockyer, Bob. "A new place for dancing," Envisioning Dance on Film and Video. Ed. Judy Mitoma. New York: Routledge, 2003. 156-162.

North Horizon. Dir., chor., perf., and ed. Thomas Freundlich \& Valtteri Raekallio. 2010. Off Ground. Dir. Boudewijn Koole. 2013.

OJO. Chor. and perf. Kim Olson. Vid., dir., and ed. Ana Baer. 2014.

Outside in. Dir. Tove Skeidsvoll. \& Petrus Sjövik. Chor. and perf. Tove Skeidsvoll. 2011.

Proximity. Dir. Chor. Garry Stewart. Vid. and Eng. Pachoud Thomas. 2013.

Strönd/Beach-Bekkur/Bænk 1,2,3,... Dir. Heike Salzer and Ingi Jensson. Chor. and ed. Heike Salzer. Perf. Saga Sigurðardóttir and Søren Linding Urup. Comp. Michael Greig. Prod. Salts. 2010. Vimeo.

The Time it Takes. Dir. Chor. and Ed. Katrina McPherson, Simon Fildes. 2013. 